\title{
Siseo y acecho. Vida del (ante)último aliento en mirlitonnades
}

( Francisco Diez

Universidad de Buenos Aires, Facultad de Filosofía y Letras, Argentina

Fecha de recepción: 12 de abril de 2021.

Fecha de aceptación: 14 de septiembre de 2021.

\section{Resumen}

En el proceso de contracción que signa la literatura de Beckett, mirlitonnades, elaborado entre 1976 y 1978, constituye un punto especialmente álgido. A pesar de la brevedad del conjunto y de sus unidades, el poemario se encuentra atravesado de un complejo de tensiones incapaces de resolverse por vía sintética. Concentradas en desplegar sus meollos paradojales, las páginas de este trabajo interrogan una serie de piezas de mirlitonnades en torno a tres ejes que han permeado, asimismo, otras zonas de la obra del irlandés -la ensayística, la prosa de ficción breve. En primer lugar, se relevan los procedimientos empleados por un lenguaje que quiere asimilarse al silencio; luego, el modo en que la voz poética delinea una vida que linda con su fin; por último, el campo de temporalidades que abre el poemario, entreverado de tres modalidades temporales heterogéneas y en lucha entre sí -el tiempo muerto, el tiempo como resto, el tiempo como flujo y reflujo. Analizar las tres conflictivas instancias ligadas entre sí implicará, pues, toparse con el impedimento de establecer un nítido discernimiento entre lenguaje y silencio, vida y muerte, aunque, a la vez, nunca terminen de confundirse.

Palabras clave: Beckett, mirlitonnades, paradoja, silencio, muerte.

\section{Hissing and Ambush. Life of the (pen)ultimate Breath in mirlitonnades}

\author{
Abstract \\ Within the contraction process that marks Beckett's literature, mirlitonnades, deve- \\ loped between 1976 and 1978, constitutes a critical point. In spite of the shortness
}


of the whole and its units, the work is heavy with tensions that cannot be solved in a synthetic way. Focused on the paradoxical cruxes, this paper interrogates a series of poems from mirlitonnades, considering three facets that have also permeated other zones of Beckett's work -his essays and his short-prose fiction. In the first place, we investigate the techniques a language uses aiming to reach the silence; secondly, the way the poetic voice outlines a life close to his end; finally, the three heterogeneous temporalities that crash in mirlitonnades -the dead time, time as a rest, time as a flux and a reflux. By analyzing these three unsettled issues we will arrive to the conclusion that it is impossible to establish a sharp distinction between language and silence, life and death -even though they never completely match.

Keywords: Beckett, mirlitonnades, paradox, silence, death.

I)

Veo mi idioma, cada vez más, como un velo que hay que rasgar para tener acceso a las cosas (o a la nada) que hay detrás [...]. Si no podemos suprimir el lenguaje, tampoco podemos perder la oportunidad de saber de qué sirve desacreditarlo. ¡Cavar un agujero tras otro, hasta que se empiece a vislumbrar lo que hay detrás, sea algo o nada! (Beckett: 1990, p.83).

Escrita hacia 1937 en alemán, la célebre esquela anuncia la cruzada a la que se abocará la literatura de Beckett. Anudando ética y estética, la misiva formula tempranamente el designio asintótico y centrípeto, inflexible y paradojal en el que Beckett, por décadas, se obstinará y profundizará: terciar el lenguaje para trizarlo, en un horizonte cuyo confín lo delimita el silencio. De la parábola contractiva que traza la literatura del irlandés, mirlitonnades, elaborado entre 1976 y 1978, constituye un punto especialmente álgido. Las páginas de este trabajo interrogan una serie de piezas del poemario en torno a tres ejes, cuyos ecos resuenan, asimismo, en otras zonas -la ensayística, la prosa de ficción breve- de la obra de Beckett: en primer lugar, los recursos reductivos de que se vale un lenguaje guiado por el afán de confundirse con el silencio; luego, la inscripción de una vida enmarcada por su ocaso, oscilando en un limbo tumulario; por último, un complejo entramado temporal, un campo de temporalidades que, por su cualidad heterogénea -el tiempo muerto, el tiempo como resto, el tiempo como flujo y reflujo-, desencadena fricciones y aporías. En efecto, ninguna de las tres enhebradas instancias se exime de meollos paradojales, circunstancia que redunda en un poemario, si bien breve y de unidades breves, atravesado de tensiones incapaces de resolverse por vía sintética.

Como si fuese una antesala o el paraje anterior en el proceso de minimización, en 1975 tiene lugar la confección y en 1976 la publicación de la breve prosa cuyo título es, por lo demás, altamente significativo: "For to end yet again". Principian el texto las siguientes líneas:

For to end yet again skull alone in a dark place pent bowed on a board to begin. Long thus to begin till the place fades followed by the board long after. For to end yet again skull alone in the dark the void no neck no face just the box last place of all in the dark the void (Beckett: 1995, p.101). ${ }^{1}$

\footnotetext{
1. "Para acabar aún cráneo solo en la oscuridad lugar cerrado frente colocada sobre una tabla para comenzar. Mucho tiempo así para empezar el tiempo que se borra el lugar seguido de la tabla ya después. Cráneo pues para acabar solo en la oscuridad vacío sin cuello ni rasgos sola la caja último lugar en la oscuridad el vacío" (2003, p.215).
} 
Por efecto de una suerte de ejercicio de oclusión emprendido nuevamente, oclusión, es dable barruntar, del complejo de procesos que avivan el cráneo, este va despejándose tanto de los elementos que atañen al orbe fenoménico como al somático. Sin embargo, cuando parecieran finalmente haberse disipado del cráneo los restantes estímulos que lo pueblan, comienzan la luz y el color a corromper el reinado vacío de lo negro: “Thus then the skull makes to glimmer again in lieu of going out. There in the end all at once or by degrees there dawns and magic lingers a leaden dawn" (ibíd.) ${ }^{2}$. Cintilan, luego, en el cráneo, un borroso espacio desértico, grisáceo, una vasta extensión de ruinas, polvo y difusas, lejanas siluetas de enanos. Y si, con todo, hacia el final del texto emerge la interrogación, con referencia al cráneo, "is this then its last state all set for always" (1995, p.103), abrigando la posibilidad, por fin, de su apagón, las palabras postreras, sin embargo, concluyen:

No for in the end for to end yet again by degrees or as though switched on dark falls there again that certain dark that alone certain ashes can. Through it who knows yet another end beneath a cloudless sky same dark it earth and sky of a last end if ever there had to be another absolutely had to be (ibíd.) $)^{3}$.

Inherente al término su secuela, desgarrado por su prosecución inexorable, "For to end yet again" insinuaría así que embarcarse en la eliminación de las imágenes y el torrente verbal que asedian la consciencia es, signada por la repetición que el título ya indica, una empresa virtualmente infinita. Ahora bien, más allá de que en esta prosa el ligue de la sintaxis ceda, por vía de la obliteración de los conectores y las vírgulas, a la abrupta yuxtaposición de palabras, en el inicio la prosa siembra la escena, o deja entrever la escenificación (el cráneo sobre una tabla) del afán de acabar -revelado, al cabo, inconducente. Así, la esfera de la que la lectura recoge la sugestión es, fundamentalmente, la esfera semántica. Si cabe postular "For to end yet again" como un preludio de mirlitonnades, no solo se debe a que este suceda cronológicamente a aquel sino principalmente a que el anhelo del término y el tropiezo del anhelo constituirán la osamenta misma de ciertos poemas del poemario, la vértebra de su morfología porfiada y concisa.

\section{II)}

Con siete décadas de vida en su haber, Samuel Beckett escribe el cúmulo de pequeños poemas que se agruparán bajo el neologismo, no sin un dejo zumbón, de mirlitonnades (entrevero de vers de mirliton, una poesía popular donde prima la rima, la flauta infantil mirlitón y su tono). Que hayan sido esbozados, según Knowlson (2014, p.673), en cuartos de hotel o en bares, en locaciones variables como París, Stuttgart o Tánger, garabateados sobre superficies innobles y circunstanciales como etiquetas de whisky, envolturas de cerveza o retazos de papel ${ }^{4}$, podría llegar a chocar con la atmósfera fúnebre que teñiría a algunas piezas. Pero el bochorno pasible de suscitar un entrecruzamiento tal se mitiga si consideramos que no es exactamente la muerte lo que campea en ellos,

2. "Se vuelve a poner pues así a hacerse todavía para acabar aún el cráneo lugar último en lugar de apagarse. Allí se levanta por último de repente o poco a poco y mágico un resplandor plomizo se sostiene” (2003, p.215).

3. "Que no pues para acabar aún poco a poco o como por conmutador la oscuridad vuelve a hacerse en fin esa cierta oscuridad que sola puede cierta ceniza. Por ella quién sabe un final aún bajo un cielo misma oscuridad sin nubes ella tierra y cielo de un final último si debiera nunca haber uno si fuese absolutamente necesario" (2003, p.218).

4. Como si el entero cuadriculado de papel blanco fuese incompatible con la ascesis de la letra, Beckett escribe poemas sin título que son (si cabe adelantarnos) restos de lenguaje sobre restos de materia. El entramado de ética de trabajo y estética que aquí, de nuevo, se manifiesta, recorrerá, modulándose, estas páginas. Remitimos a una disertación de Lucas Margarit donde aborda, entre otras cosas, la reutilización y resignificación de la materia en Beckett: https://www.youtube.com/ watch?v=0fSxZ8yimUI 
sino su vecindad, y que lejos está de predominar el tono de apesadumbrado lamento, sino la variedad de registros e inflexiones de la voz. En efecto, dos condiciones ligadas entre sí, extractables de dos versos del poemario, impulsan la serie de escarceos con la proximidad del fin: una instancia temporal ("ne plus en avoir pour longtemps" (Beckett: 2000, p.236) $)^{5}$ y una modulación o declinación de la voz ("un dernier murmure" $(2000, \text { p.246) })^{6}$. Poco falta para el fin y tenue es el hilo de la voz: temporal y vocal, el doble marco, que ciñe y cataliza la emergencia de la escritura, atrae también el límite con el que los poemas se topan, el desfasaje infinitesimal, infranqueable e irreductible alrededor del cual se agolpan y se revuelven: la imposibilidad de la fundición total del lenguaje en el silencio, de la vida, aunque exigua, en la muerte. La brecha mínima que, sin embargo, inocula la errancia desterrando el engarce, evoca la reflexión sobre la muerte que lleva adelante Maurice Blanchot:

En esta perspectiva, la muerte [...] es lo que no le ocurre a nadie, la incertidumbre y la indecisión de lo que no ocurre nunca, lo que no puedo pensar con seriedad, porque no es seria, es su propia impostura, el desmoronamiento, la consumación vacía, no el término, sino lo interminable; [...] no la muerte verdadera, sino, como dice Kafka, la risa sarcástica de su error capital (1969, p.145).

Ella no acaece, pero, no obstante, la obcecación no cesa. Bajo esta luz, entonces, puede leerse el poema siguiente:

imagine si ceci
un jour ceci
un beau jour
imagine
si un jour
un beau jour ceci
cessait
imagine (2000, p.190).

El verbo que escande los versos al reiterarse pareciera señalar una ávida instigación; el imperativo de una voz que hacia sí misma dirige su interpelación; una prótasis obstinada en su apódosis. Ahora bien, si la incitación consiste en imaginar el cese de "esto" -cese que, por otra parte, como podría hacer suponer la sonoridad estrecha entre "ceci" y "cessait", cierne de cerca a su objeto-, ¿qué encierra este deíctico en que se cifra el celo del poema? La indeterminación del deíctico promueve a decantarnos por una alternativa plural: diríamos que "esto" implica el día, los días, la reiteración de los días, pero también "esto" es el poema mismo, su espoleo a imaginar el cese, su puñado repetido de palabras, en definitiva, su lenguaje. El poema, pues, acicatea su disolución (y el acabamiento de los días), pero, sin embargo, lo obtura a la vez: la última palabra, la misma con la que comienza (y recordemos que ninguno de los poemas de mirlitonnades principia con mayúsculas), augura la iteración, sin fin, del proceso del cese, el recomienzo del deseo de acabar con la repetición, repetición que vertebra el poema. Y así indefinidamente. En otras palabras, el modo en que está construido el poema es aquello a lo que el deseo del poema instiga a cesar, aquello que, en virtud de la disposición del poema, degenera en imposibilidad de cesar.

\footnotetext{
5. "ya no falta mucho" (2000, p.235).

6. "con el aliento del final" (2000, p.247).

7. "imagina si esto / si un día esto / un día feliz / imagina / si un día / un día feliz esto / se acabara / imagina" (2000, p.191).
} 
Así, el loop, el encarnizamiento implosivo que no se consuma, la tensión de fuerzas centrífuga y centrípeta, remite a la caracterización que del purgatorio joyceano hace Beckett, contraponiéndolo al de Dante, en su "Dante...Bruno.Vico..Joyce":

In the one, absolute progression and a guaranteed consummation: in the other, flux - progression or retrogression, and an apparent consummation. In the one movement is unidirectional, and a step forward represents a net advance: in the other movement is nondirectional -or multi-directional, and a step forward is, by definition, a step back (1984, p.31) ${ }^{8}$.

Una afirmación realizada unas páginas antes en el mismo ensayo resuena como un eco de la cita: "The maximum of corruption and the minimum of generation are identical: in principle, corruption is generation" (1984, p.19) ${ }^{9}$. Ahora bien, el vocablo "generación" (y el contexto de la cita) se inscribe en el ámbito, no ya del lenguaje, sino de la vida. A partir de este ligero deslizamiento, despunta un campo de afectación mutua (que impregna fuertemente a mirlitonnades): las tensiones y las aporías que convulsionaban al lenguaje del poema tienden a derramarse y contaminar las consideraciones que atañen al territorio vital: "The consciousness that there is a great deal of the unborn infant in the lifeless octogenarian, and a great deal of both in the man at the apogee of his life's curve, removes all the stiff interexclusiveness that is often the danger in neat construction" $(1984, \text { p.20 })^{10}$. Como el poema, el pasaje acusa un trastorno en el orden del fin y del comienzo. Precisamente, el vértice que triangula este reino de torsiones e invaginaciones es el tiempo, una determinada concepción del tiempo que un verso de "Dieppe", poema gestado unas tres décadas antes que mirlitonnades, expresa condensadamente: "encore le dernier reflux" (2000, p.148) ${ }^{11}$. Alabeada, oximorónica temporalidad, donde lo último, lo que es sin retorno, sin embargo, regresa, donde lo último, no siendo lo último, refluye.

\section{III)}

Las agitaciones, inestabilidades y pugnas -notoria singularidad de mirlitonnades- se encarnan materialmente en el poema al extremo prieto. Cabal ejemplar de tal inscripción es la siguiente pieza:

$$
\begin{aligned}
& \text { rêve } \\
& \text { sans fin } \\
& \text { ni trêve } \\
& \text { á rien }\left(2000, \text { p.222) }{ }^{12}\right. \text {. }
\end{aligned}
$$

Casi monofónica, la dimensión sonora del poema observa, primero, una rima alternada, de la que es preciso subrayar la de "fin" y "rien" -el fin, aquí, no es nada-; luego, la estrecha sonoridad de las dos palabras del segundo verso y la iteración de la consonante vibrante. En paralelo, al mirar las letras de las palabras del poema se distingue

\footnotetext{
8. "En uno hay progresión absoluta y consumación garantizada; en el otro, flujo -progresión o regresión-y una consumación aparente. En uno el movimiento es unidireccional, y un paso adelante significa un avance neto; en el otro el movimiento es no direccional, o multidireccional, y un paso adelante es, por definición, un paso atrás" (2008, p.45).

9. “La corrupción máxima y la generación mínima son idénticas: en principio, corrupción es generación” (2008, p.31).

10. "La conciencia de que hay mucho del niño no nacido en el octogenario decrépito, y mucho de ambos en el hombre que está en el apogeo de su curva vital, elimina toda la rígida interexclusividad que suele afectar las construcciones ordenadas" (2008, p.33).

11. "de nuevo el último reflujo" (2000, p.149).

12. "sueño / sin fin / ni tregua / en nada" (2000, p.223).
} 
la disposición de este a partir de un juego de mínimos desplazamientos entre aquellas: las dos primeras letras (la primera palabra) del tercer verso son las dos últimas del segundo inversamente colocadas; de "rêve" a "trêve" media una mera letra de diferencia. Desde el punto de vista de la significación semántica, cabe aislar el rasgo temporal, lo interminable, lo incesante, el sin fin del sueño. Así, el poema alude a lo interminable bajo la máxima contracción formal. La nada que sin fin se sueña en el poema es aquella que exasperadamente la forma se empeña en materializar; la forma sueña con su encogimiento extremo, confinarse hacia su nada, pero el poema la despierta bruscamente afirmando que no hay fin, que el fin es nada, no toma cuerpo sino en la evanescencia del sueño. Cuatro versos, siete palabras y nueve letras, el empastamiento físico del poema, su ensimismamiento larval, gráfico y sonoro, auditivo y visual, estrechando las últimas, minúsculas palabras que quedan, pareciera querer soñar con reducirlas a una sola, solo soplo mínimo, para que, ceñido de silencio, acabase por desvanecerse en él.

De aquí, pues, su similitud con el gesto del siseo. Sisear, en efecto, consiste en emitir un sonido (el chistido) con miras exclusivas a producir a silencio; solo que, emitiendo el sonido, se obstruye precisamente lo pretendido. Todo sucede entonces como si el único, ínfimo sonido que profiriese el poema fuese aquel que lo instase a callarse, siseo que no chistase a nada sino a sí mismo, pero que, realizándose, desrealiza el silencio. Con todo, los afanes por hacer del poema el tránsito murmurante del lenguaje al silencio no podrían armonizar con el siguiente andamiaje reflexivo:

La forma que pretende dar cuenta de dicho murmullo -imprescindible a la composición de mirlitonnades- se auto-legitima [...]. El tipo de aforismo al que Beckett llega alcanza un punto de irreductibilidad extrema donde se permite su autonomía como texto [...]. Despalabra ésta que, a su vez, más que pedir, exige una estética que la soporte, que le de sustentación para pintar el vacío interior, aquello que es no-mimético de un mundo objetivamente a-referencial, de forma que, por referencialidad, tan solo existe el propio texto. (Souza Pimentel: 2011, pp.212-213. Los destacados son nuestros).

La señalada "autonomía del texto" supone un determinado carácter del lenguaje que es menester reponer. Se parte de la existencia de un hiato entre la palabra y el referente y la existencia de una brecha entre la palabra y la interioridad del sujeto - por lo demás, cualquier cristal de interioridad, por frágil y veleidoso que sea, es inescindible del cuerpo de palabras que provisoriamente lo monta. Todo lo preside una incompatibilidad radical. De este modo, la paroxística reducción y el despojamiento cerril devienen el recurso para manifestar y dar cuenta del enclave solitario en que el lenguaje flota - y, atravesándonos, fluye. Densificación corpuscular, el poema en mirlitonnades se sustenta y corresponde a esta manera de concebir el lenguaje; de aquí provendría su autorreferencialidad. No pretendemos recusar el hiato que abisma los ámbitos y aísla al lenguaje. Pero, pese a todo, el poema no se satisface con referirse a sí mismo y ser solamente el "soporte" de sí mismo. La palabra, en cambio, si vuelve sobre sí misma, si, en efecto, se aprieta, si la palabra, afanosamente, retorna sobre sí misma lo hace para remover ese sí mismo, disminuirlo al esquilmarlo y así, en su límite (que coincide con su imposibilidad) deslizarse evanescentemente hacia el silencio. La palabra no quiere permanecer sino pasar; su destino y su móvil lo imanta el "afuera". En esta dirección, puede recogerse la afirmación de Michel Foucault enunciada El pensamiento del afuera:

Se acostumbra creer que la literatura moderna se caracteriza por un redoblamiento que le permitiría designarse a sí misma; en esta autorreferencia, habría encontrado el medio a la vez de interiorizarse al máximo (de no ser más que el enunciado de sí misma) y de manifestarse en el signo refulgente de su lejana existencia. De hecho, el acontecimiento que ha dado origen a lo que en un sentido estricto se entiende por 'literatura' no pertenece al orden de la interiorización más que 
para una mirada superficial; se trata mucho más de un tránsito al 'afuera' [...]. La literatura no es el lenguaje que se identifica consigo mismo hasta el punto de su incandescente manifestación, es el lenguaje alejándose lo más posible de sí mismo [...] este ponerse 'fuera de sí mismo' (...) revela una dispersión más que un retorno de los signos sobre sí mismos (1989, pp.12-13).

Pero, ¿este último término, "dispersión", no iría a contrapelo del ejercicio beckettiano de contracción? Ciertamente. No obstante, la acción dispersiva ${ }^{13}$ y el despojamiento contractivo se aúnan en tanto buscas empeñadas en movilizar la identificación del lenguaje consigo mismo, en desenraizar, diseminándolo o comprimiéndolo, su subsistencia estable.

Separado, entonces, de la referencia y del sujeto, el lenguaje posee, no obstante, una particularidad sobre la que descansa la posibilidad de transitar y devenir silente. En efecto, tal dimensión del lenguaje se encuentra ligada al tiempo. Dice un poema de mirlitonnades:

flux cause
que toute chose
tout en étant
toute chose
donc celle-là
même celle-là
tout en étant
n'est pas
parlons-en $(2000, \text { p.194 })^{14}$.

En la huella, acaso, de Heráclito ${ }^{15}$, pareciera primero el poema aludir a la alteración que el tiempo, en tanto flujo, imprime en los objetos; el pasaje perpetuo del tiempo niega la estabilidad de las cosas, les sustrae su fijeza y su zócalo. El último verso, sin embargo, redimensiona el poema prescribiéndole una exigencia e infundándole un espesor: "parlons-en" ... hablemos de ello, hablemos del flujo. ¿Qué implica que el flujo sea (la) cuestión del lenguaje? Por una parte, se trata de que el lenguaje nos recorre y nos atraviesa, del que no somos señor sino juguete, menos la premisa que la superficie porosa por la que circula y retoza. Pero, además y a partir de ello, implica que la negatividad que lleva consigo el flujo del tiempo impregna también al lenguaje. El lenguaje, como el tiempo -que corroe los objetos y los dessustancializa-, está dotado de un poder de erosión. Pero, desde "La carta alemana" a mirlitonnades, el blanco de la erosión se especifica: es contra lenguaje mismo que atenta la erosión capaz de infligir el lenguaje; él posee la capacidad, dispuesto de cierta manera, de hacerse callar, de sisearse. Lo que equivale a plantear que él puede hacer suyos los poderes del silencio y redirigirlos hacia sí. Por lo tanto, en sintonía con lo que el Beckett ensayista postulaba, a saber, que no media una separación tajante entre la vida y la muerte, entre el apenascon-vida del infante y el todavía-no-muerto del anciano, es dable pensar que no hay un antagonismo polar entre el lenguaje y el silencio, pero que, tampoco, se confunden. La pura nada silenciosa, sin restos, no pertenece, sugería el poema, más que al sueño. Pero, a la vez, son estos restos mínimos, en la mínima distancia que resta del silencio, trabajados por él y tendiendo, tenaces, hacia él, hacia su desaparición, son estos restos lo que, vida exánime del habla, murmura en mirlitonnades.

13. Con que Foucault designa, por otra parte, el movimiento de las ficciones de Blanchot.

14. "flujo causa de que / cada cosa / sin dejar de ser / cada cosa / por consiguiente aquella / incluso aquella / que sigue siendo / no lo es/ hablémoslo" (2000, p.195).

15. Una de las consecuencias, en efecto, de la ascesis del poema, es la volatilización de las huellas intertextuales que en la poesía de Beckett, anteriormente, se manifestaban de manera más o menos flagrante. 


\section{IV)}

Vida exánime del habla, pero también vida exánime sin más. Parejamente, jalonan mirlitonnades restos de la lengua y alusiones a una vida a la que pareciera que le resta poco tiempo de vida, tiempo en el que es un resto lo que queda de vida. En este sentido, la circunstancia biográfica de un Beckett septuagenario es menos una matriz que un aditamento, pues es en el poema mismo donde se ponen en juego los conflictos del vivir en víspera del obituario:

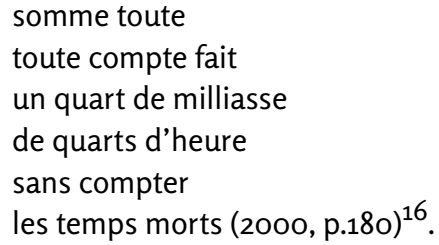

El gesto que, a primera vista, enuncia el poema podría considerarse característico de la etapa crepuscular de la vida: el aproximarse de la noche desencadena el recuento de la vida vivida, la cuenta (y el cuento) del tiempo y de las horas vividas, en un afán de síntesis o de reunión: llevar a cabo la summa de la vida. Ahora bien, el ocaso de la vida, en tanto etapa vital central del poemario, comprende una temporalidad que exige especificarse. Un posible ángulo de inserción podría brindarlo El tiempo que resta, donde Agamben analiza una experiencia del tiempo que denomina tiempo mesiánico. Dice al respecto el italiano: "el tiempo mesiánico no es el final del tiempo, sino el tiempo del final (...) no es el último día, no es el instante en el que concluye el tiempo, sino el tiempo que se contrae y comienza a acabarse (...) [es] el tiempo que resta entre el tiempo y su final" (2006, p.68). Tiempo del fin, ya que no el fin del tiempo, aquel no se subsume "ni [en] el tiempo cronológico ni [en] el éschaton apocalíptico [vale decir, el ulterior tiempo del otro mundo, la eternidad atemporal que seguiría a este mundo]; es - una vez más - un resto, el tiempo que queda entre estos dos tiempos" (ibíd.). Si, por un lado, este enclave, que intercala un pliegue de tiempo en el tiempo, una cápsula temporal donde el tiempo se enrolla y se abrevia, podría asimilarse al cuño temporal ("ne plus en avoir pour longtemps") que circunscribe mirlitonnades, allí donde se abre la tentativa del recuento; por otro, la argumentación de Agamben se dirige hacia un punto ante el cual, a los efectos del análisis de la temporalidad propia del poemario, cabe introducir un matiz diferencial. Agamben distingue el tiempo mesiánico del "tiempo de transición" (2006, p.74) que, por su "dilación implícita (...) tiende a protraerse al infinito y a hacer así inaprehensible el fin que ella [la transición], por el contrario, debería producir” (ibíd.). El primero, en cambio, implica "una transformación actual de la experiencia del tiempo, capaz de interrumpir aquí y ahora el tiempo profano [el chronos, el tiempo cronológico]" (2006, p.77. El destacado es nuestro). El declinante momento en que surge el conteo no implicaría tanto una interrupción, sino, antes bien, una suspensión, ligada al tiempo de transición.

El poema encierra la clave de esta distinción. Cuando se hace la cuenta, diríase, total, cuando se suma todo, es allí donde las horas, de un verso al otro, sorprenden la aprehensión del conteo descomponiéndose, fragmentándose en cuartos de cuartos. En la hora de la integración, el tiempo cronológico aparece inmenso y cuarteado, burlándola y escurriéndosele, y ello constituye un movimiento en el que, llamativamente, en su "Proust", había reparado ya el mismo Beckett: "en el mejor de los casos, todo lo realizado en el Tiempo (todo lo que el Tiempo produce), sea en el Arte o en la Vida, solo puede 
poseerse sucesivamente, mediante una serie de anexiones parciales, y nunca en forma integral y de una vez" (2008, p.53). Ingente, estriado, el tiempo se declara refractario, entonces, al cuento y recuento sintetizadores. Incluso "sans compter", incluso si se deja de lado "les temps morts".

¿Qué ocurre en el poema con los tiempos muertos? En principio, en el recuento, que querría acaparar la suma de las horas, los tiempos muertos no cuentan. Habría una heterogeneidad; la medida de los tiempos muertos no sería homologable a la del tiempo cronológico. En este sentido, si las horas pertenecen al tiempo vivido, tiempo del cual se quiere la summa, ¿qué relación hay entre los tiempos muertos y la muerte? Asaz significativo es el tratamiento que sobre este nudo realiza Blanchot:

ese tiempo no es la inmovilidad ideal que se glorifica con el nombre de eterno [...] el tiempo muerto es un tiempo real donde la muerte está presente, llega, pero no deja de llegar, como si llegando, volviese estéril el tiempo por el cual puede llegar. El presente muerto es la imposibilidad de realizar una presencia (1969, pp.24-25).

Llegando: en el tiempo muerto, dice Blanchot, se sustrae el presente en el cual la muerte podría hacerse presente; el presente, allí, pasa del presente al gerundio, la inminencia remueve al término, que circunda pero no comparece. $Y$ es por ese tiempo que se dice en gerundio - sin el aquí y ahora, asideros de la interrupción agambeniana-, merced a que la muerte se vuelve una errática instancia que no termina de hacerse plenamente presente, por lo que no sería descaminado asimilar el tiempo que permea al poemario con la suspensión, extendida sobre la duración que destila el gerundio, antes que con la interrupción, que marca el presente con su corte, instituyente de un fin. Y, sin embargo, aquí tampoco debería regir una rígida división. En la medida en que atrae al lenguaje del poema la posibilidad silente del cese y la interrupción, él porfía en el pasaje pero se suspende en su borde, no termina de coincidir con la interrupción total. En tanto tiempo suspendido a la par que contraído, designando una duración crepuscular, el tiempo muerto, entonces, acabándose, podría considerarse un tiempo-resto, tiempo residual que impide la cerrazón del círculo de la síntesis.

La ausencia de fin, sin embargo, no es correlativa de un mood quedo, de una variable tonal retirada en la abulia y el lamento. No pareciera, por cierto, participar de una inflexión acongojada el fraseo del francés coloquial que modula los primeros dos versos del último poema examinado. Asimismo, el poema que anuncia la inminencia del fin replica, ante tal tesitura, con una flagrante socarronería:

à l'instant de s'entendre dire

ne plus en avoir pour long temps

la vie à lui enfin sourire

se mit de toutes ses dents $\left(2000\right.$, p.236) ${ }^{17}$.

La repetición, además, estructurante de algunos poemas, se lee menos como un automatismo lánguido que como una insistencia, concisa, es cierto, pero ávida. A raíz de esto podemos, finalmente, dimensionar la complejidad temporal -las varias modalidades temporales coexistentes y en tensión- que entraña mirlitonnades, en cuya órbita gravitan y se agitan su lenguaje y la añosa vida. 
La vida que orilla la ida instala en mirlitonnades una instancia crepuscular, un tiempo de transición donde la muerte es inminente para el resto que queda de vida. Este, sin embargo, no es acaparado plenamente, en virtud de otro movimiento temporal, el retorno. El lenguaje, por su parte, como el flujo del tiempo, capaz de investirse de los poderes del negativo, puede volverlos hacia sí, articularse como emisiones de un siseo que insta a disminuirse y asordinarse. Obstinado y casi sin vida, el aliento de la voz, entreverado de hálitos de silencio, desciende por la pendiente de una monofonía en pos de transparentarse con el silencio. El aliento reducido y la exigüidad de la vida, empujados por flujos de negativo, son devueltos, sin embargo, cuando se estrechan contra el confín, por el reflujo: el retorno, en efecto, hace refluir los restos, remonta las esquirlas resultantes de la máxima contracción. Que lo último no sea lo último, intercalar un desfasaje intersticial en el encuentro de lo último consigo mismo, allí donde se emplaza la suspensión, tal es el cociente de la acción del reflujo. Y tales son las paradojas que signan mirlitonnades, el impedimento para el análisis de establecer un nítido discernimiento entre suspensión e interrupción, lenguaje y silencio, vida y muerte.

En "El lenguaje al infinito", Foucault circunscribe uno de los propósitos, tan añejo como central, de la escritura: escribir para no morir. "El discurso, ya se sabe, tiene el poder de retener la flecha, ya lanzada, en un retraimiento del tiempo que es su espacio propio" (1996, p.143). El ardid de que se vale la escritura para alzarse contra la venida del fin consiste en su reduplicación infinita; escritura que no se escribe sino a sí misma y que, ajena a la referencia, puede extenderse indefinidamente. Dice Foucault: "El lenguaje, sobre la línea de la muerte, se refleja: halla en sí como un espejo; y para detener esa muerte que va a detenerlo, solo tiene un poder: el de alumbrar en sí mismo su propia imagen dentro de un juego de lunas que no tiene límites" (1996, p.144). Foucault, en el ensayo, retoma a Blanchot, de quien extrae ese posible afán dilatorio de la escritura. Pero Blanchot ha dado, también, con el anhelo y el gesto paradójicos que parecieran movilizar la escritura de mirlitonnades: "escribir para poder morir" (1969, p.85. El destacado es del autor). Al acecho del pasaje, en aras de pasar, el murmullo del poema sisea... una y otra vez, una y otra vez, sí, se sisea. 


\section{Bibliografía}

"Agamben, G. (2006). “Cuarta jornada: Apóstolos”. En: El tiempo que resta, pp.: 65-91. Madrid: Trotta.

»Beckett, S. (1984). "Dante...Bruno. Vico... Joyce”. En: Disjecta. Miscellaneous writings and a dramatic fragment. New York: Grove Press. Disponible en: https://b-ok.lat/s/samuel\%2obeckett. [24-12-2020].

"Beckett, S. (1990). "La garganta del silencio. Una carta alemana de Samuel Beckett”, en Utopías. Revista de la Facultad de Filosofía y Letras de la UNAM, 6, 82-83.

» Beckett, S. (1995). "For to end yet again". En: The complete short prose, 19291989. New York, Grove press. Disponible en: https://b-ok.lat/s/samuel\%2O beckett. [24-12-2020]

» Beckett, S. (2000). Obra poética completa. Madrid: Hiperión.

» Beckett, S. (2003). “Para acabar aún”. En: Relatos, pp.:215-219. Barcelona: Tusquets.

» Beckett, S. (2008). Proust y otros ensayos. Santiago de Chile: Universidad Diego Portales.

》 Blanchot, M. (1969). El espacio literario. Buenos Aires: Paidós.

»Foucault, M. (1989). “Miento, hablo”. En: El pensamiento del afuera, pp.:7-15. Valencia: Pre-textos.

» Foucault, M. (1996). “El lenguaje al infinito”. En: De lenguaje y literatura, pp.:143157. Barcelona: Paidós.

"Knowlson, J. (2014). “Twenty four- Politics and Company 1977-9”. En: Damned to fame. The life of Samuel Beckett, pp.: 673-674. Londres: Bloomsbury electronic edition. https://b-ok.lat/s/samuel\%2obeckett. [24-12-2020]

»Souza Pimentel, T. (2017). "Lo inevitable. Una mirada estética del fracaso". En: Margarit, L. y Montes, E (comps.), Segundas jornadas de literatura inglesa. 110 año del nacimiento de Samuel Beckett, pp.: 211-219. Buenos Aires: Editores Argentinos. 
